\title{
New treatments for keratoconus
}

\author{
Emilio Pedrotti - Chiara Chierego - Erika Bonacci - Alessandra De Gregorio • \\ Arianna De Rossi · Andrea Zuliani · Adriano Fasolo · Giorgio Marchini
}

Published online: 15 June 2020

(C) Springer Nature B.V. 2020

Keratoconus $(\mathrm{KCN})$ is a bilateral asymmetric disorder which selectively affects corneal stroma causing progressive bulging, thinning, and biomechanical instability. The typical presentation is astigmatism with progression trend towards irregularity, high order aberrations (coma), and visual impairment with reduced quality of life [1]. Despite being considered a rare disease, $\mathrm{KCN}$ epidemiology appears to be changing rapidly. Prevalence and incidence data are variable among different countries and depend on diagnostic technologies employed, but according to a recent meta-analysis, the estimated prevalence of $\mathrm{KCN}$ in the world is $1.38 / 1000$ [2]. $\mathrm{KCN}$ affects typically adolescence and progresses until the third or fourth decade of life so the impact of this disorder is to be taken into account for the involvement of the

E. Pedrotti $(\bowtie) \cdot$ C. Chierego · E. Bonacci ·

A. De Rossi - A. Zuliani - A. Fasolo - G. Marchini

Ophthalmic Unit, Department of Neurosciences,

Biomedicine and Movement Sciences, University of

Verona, Verona, Italy

e-mail: emilio.pedrotti@univr.it

C. Chierego

e-mail: chiara.chierego@aovr.veneto.it

E. Bonacci

e-mail: bonaccierika89@gmail.com

A. De Rossi

e-mail: arianna.de.rossi91@gmail.com productive categories of the society; moreover, the economic burden of $\mathrm{KCN}$ represents a significant public health concern due to the rise in lifetime cost of affected patients [3, 4].

Many treatments (both medical and surgical) have been developed in the last years to halt its progression and improve the outcome, but the management is still challenging. Many KCN patients need more than one treatment throughout their lives. The goal of $\mathrm{KCN}$ treatment changes according to the stage of the disease [5]. In the early stages, the refractive defect can be corrected with spectacles and contact lenses (CL): a wide variety of options are available on the market ranging from soft lenses and soft toric, to piggy-back and hybrid lenses. New technological advancements have led to the development of customized,

A. Zuliani

e-mail: andreazuli92@gmail.com

A. Fasolo

e-mail: adriano.fasolo@yahoo.it

G. Marchini

e-mail: giorgio.marchini@univr.it

A. De Gregorio

Ophthalmic Unit, San Bassiano Hospital,

Bassano del Grappa (VI), Italy

e-mail: a.degregorio@icloud.com 
aberration-controlling $\mathrm{CL}$, such as customized soft and scleral lenses [6, 7]. Nevertheless, with the progression of the disease, the correction with lenses becomes unsatisfactory or impossible due to the development of irregular astigmatism, CL intolerance, and corneal opacity.

In 1997, CXL (corneal crosslinking) was first introduced to the clinical management of $\mathrm{KCN}$ to halt the progression of the disease in the early stages [8]. CXL produces a stiffening of the cornea by means of a photochemical reaction that occurs after the stroma is soaked with riboflavin (B2 vitamin isomer) and then irradiated with UVA light, to result in a stabilization of the disease in the early stages [9]. Many procedures to perform CXL have been developed over time targeting to optimize its duration and phases in order to improve the topographic outcomes. The original long-lasting Dresden protocol has been overcome by accelerated high fluence protocol to limit phototoxicity [10]. Epithelium off technique seemed to be the most encouraging method to ensure a deep penetration of riboflavin into the stroma; on the other hand, this strategy involves epithelium removal and related complications. A solution has been proposed with "epithelium on" techniques, relying on different strategies to allow B2 vitamin penetration, like new riboflavin formulations with added corneal enhancing compounds (benzalkonium chloride, sodium ethylenediaminetetraacetic acid) or iontophoresis-assisted CXL [11-13]. However, clinical trials comparing standard and transepithelial CXL showed better outcomes with the standard technique, while the transepithelial approach yield also an increase in topographic parameters $(\mathrm{Kmax})[14,15]$. CXL in combination with other procedures (CXL PLUS) allows not only the stabilization of the disease but also a partial (in most cases) or total refractive correction to provide patients with better visual acuity: CXL and Photorefractive Keratectomy (PRK), CXL and Transepithelial Phototherapeutic Keratectomy (PTK), CXL and Intrastromal Corneal Ring Segment (ICRS) implantation, and CXL and phakic Intraocular Lens Implantation [16]. A 6-year follow-up study on simultaneous topography-guided PRK and CXL (SimLC) showed that corneal flattening amounts on average to 5.9 D with SimLC, while CXL alone (70\% of eyes) flattens by 2.1 D. In addition, authors demonstrated that SimLC provided permanent stability at the end of follow-up. If on the one hand it is true that PRK reduces corneal strength by approximately 5-10\%, on the other hand CXL strengthens the cornea by around $70 \%$; so the synergy of the two procedures creates a reshaped and also stronger cornea, thus promising more stability [17].

With the progression of $\mathrm{KCN}$, the astigmatism and the irregularity of the cornea increase and CXL is not the indicated treatment because the goal is no longer to stabilize the cornea, but to regularize it.

Intrastromal corneal ring segments (ICRS) are surgical inserts made of polymethyl methacrylate and implanted in the deep stroma. They are able to reduce corneal distortion by flattening the steep area of the cornea and reshaping it, to reduce coma and comalike aberrations, and to increase CL tolerance and delay keratoplasty $[18,19]$.

Intacs (Addition technology Inc.) and Ferrara (Ferrara Ophthalmics) rings are the most used types of ICRS for the management of keratoconus [20, 21]. The intrastromal channel for ICRS implantation was initially sculpted mechanically, but currently FSLassisted technique has become the most popular choice for its effectiveness and precision [22]. Nowadays, implantation nomograms, specific indications, and contraindications for ICRS implantation for each case are available to maximize the safety and efficacy of the treatment [19].

Combined therapeutic approach of CXL and ICRS leads to an increase in biomechanical corneal stiffness and stability which has proven useful in progressive keratoconus [23].

As the disease progresses, there are important changes affecting the corneal architecture and its transparency and partial or complete substitution of corneal tissue is needed.

When Descemet-endothelium complex (DEC) is compromised, a whole corneal transplantation (PKP) is indicated. When DEC is healthy, the DALK (deep anterior lamellar keratoplasty) technique is the preferred surgical option. However, the number of DALK performed is largely variable between different countries [24]. Surely one crucial aspect in DALK is that an optimal visual outcome depends on the absence of optical interface between deep stromal layers, obtained by the detection of the ideal cleavage between deep stroma and Descemet membrane (DM): Dua's layer [25]. The big-bubble (BB) technique was developed to fulfill this need and shows earlier vision improvement compared to partial 
stromal removal leaving an uneven cleavage plane [26]. However, the technical difficulty, intra-operatory complications, such as DM perforation, limit DALK performance. Furthermore, its reproducibility depends on the level of experience of the surgeon. The use of femtosecond laser (FSL) can help standardize DALK procedure by reducing bias related to manual cuts [27].

FSL-integrated optical coherence tomography (iOCT) was recently used for direct visualization and calibration to perform precise anterior lamellar and side cuts for the removal of the anterior stroma [28].

FSL-assisted keratoplasty is performed with great accuracy and efficacy, many cutting patterns have been developed to increase host-graft apposition (tophat, mushroom, zig-zag), minimizing post-operative astigmatism and improving visual outcome [29, 30].

Moreover, FSL allows the creation of precise cuts into the corneal stroma to create pockets in which can be inserted devices to regularize corneal curvature like ICRS, or corneal stroma lenticules to restore thickness and mechanical stability by a tissue additive procedure (additive keratoplasty, AK). AK consists in the insertion of a corneal lamella, obtained from a human donor cornea (HDC) or from a lenticule extraction procedure, within the ectatic area to restore the lost thickness, and reduce the conic protrusion. This surgical technique takes advantage of FSL both for the creation of the lenticule (in HDC) and for the intrastromal pocket shaping [31, 32]. The initial results show feasibility, safety, and clear lenticules. The main advantages of these techniques are their minimal invasiveness, low risk of immune rejection, no stitches, shorter surgery duration, and the use of topical anesthesia. However, stromal allograft rejection is still possible, so studies on the decellularization of the lenticules aim to reduce or halt the immune response without affecting the collagen architecture [33]. Furthermore, once restored corneal thickness and biomechanics, excimer refractive treatment is allowed, thus opening up new chances to improve visual outcome to KCN patients [19, 34]. CXL can play a role also in advanced stages which already underwent lamellar or penetrating keratoplasty, by improving biomechanical and topographic indices in recurrent keratoconus (RKC) [35]. Some authors proposed AK combined with CXL to strengthen treatment of mild-to-moderate keratoconus [36] or
CXL combined with excimer refractive treatment after AK to prevent secondary ectasia [19, 34].

Among the emerging techniques for advanced stages, there are also Bowman layer transplantation (BLT) and gene therapy [37]. BLT is a mini-invasive technique that reinforces and flattens the cornea with secondary more comfortable CL wearing and stabilization of the ectasia slowing down disease progression and delaying the need for DALK or PKP [38].

Gene therapy is another innovative option to address KCN. Many studies have shown a genetic component in the etiology of the disease and genomewide analyses have identified mutations and genomic loci likely to play a role in $\mathrm{KCN}$ development. Biophysical properties of the cornea (immune privilege, transparency, and stability) make this tissue an appropriate candidate for gene therapy. The basics of the technique are the same as for other tissues: the target gene sequence is modified by means of a viral vector which integrates into the cell DNA. The modified sequence provides translation of a healthy and functional protein so that the disease could be healed $[39,40]$. Despite recent advantages in vectors and in the ability to modulate corneal milieu to increase gene therapy acceptance, more studies are still needed.

The aim of the topical collection "New treatments for $\mathrm{KCN}$ " is to draw attention to the various treatments available, providing the reader with an overview on the options, their upsides, their limitations, and their possible future developments.

\section{Compliance with ethical standards}

Conflict of interest The authors declare they have no conflict of interest.

\section{References}

1. Ferdi AC, Nguyen V, Gore DM, Allan BD, Rozema JJ, Watson SL (2019) Keratoconus natural progression: a systematic review and meta-analysis of 11529 eyes. Ophthalmology 126(7):935-945. https://doi.org/10.1016/j. ophtha.2019.02.029

2. Hashemi H, Heydarian S, Hooshmand E et al (2020) The prevalence and risk factors for keratoconus: a systematic review and meta-analysis. Cornea 39(2):263-270. https:// doi.org/10.1097/ICO.0000000000002150

3. Rebenitsch RL, Kymes SM, Walline JJ, Gordon MO (2011) The lifetime economic burden of keratoconus: a decision analysis using a markov model. Am J Ophthalmol 
151(5):768-773.e2. https://doi.org/10.1016/j.ajo.2010.10. 034

4. Chan E, Baird PN, Vogrin S, Sundararajan V, Daniell MD, Sahebjada S (2019) Economic impact of keratoconus using a health expenditure questionnaire: a patient perspective. Clin Exp Ophthalmol. https://doi.org/10.1111/ceo.13704

5. Andreanos KD, Hashemi K, Petrelli M (2017) Keratoconus treatment algorithm. Ophthalmol Ther. https://doi.org/10. 1007/s40123-017-0099-1

6. Katsoulos C, Karageorgiadis L, Vasileiou N, Mousafeiropoulos T, Asimellis G (2009) Customized hydrogel contact lenses for keratoconus incorporating correction for vertical coma aberration. Ophthalmic Physiol Opt 29(3):321-329. https://doi.org/10.1111/j.1475-1313.2009.00645.x

7. Jinabhai AN (2020) Customised aberration-controlling corrections for keratoconic patients using contact lenses. Clin Exp Optom 103(1):31-43. https://doi.org/10.1111/cxo. 12937

8. Spörl E, Huhle M, Kasper M, Seiler T (1997) Artificial stiffening of the cornea by induction of intrastromal crosslinks. Der Ophthalmol 94(12):902-906. https://doi.org/10. 1007/s003470050219

9. Wollensak G, Spoerl E, Seiler T (2003) Riboflavin/ultraviolet-A-induced collagen crosslinking for the treatment of keratoconus. Am J Ophthalmol 135(5):620-627. https://doi. org/10.1016/S0002-9394(02)02220-1

10. Ting DSJ, Rana-Rahman R, Chen Y et al (2019) Effectiveness and safety of accelerated $\left(9 \mathrm{~mW} / \mathrm{cm}^{2}\right)$ corneal collagen cross-linking for progressive keratoconus: a 24-month follow-up. Eye 33(5):812-818. https://doi.org/10. 1038/s41433-018-0323-9

11. Kissner A, Spoerl E, Jung R, Spekl K, Pillunat LE, Raiskup F (2010) Pharmacological modification of the epithelial permeability by benzalkonium chloride in UVA/Riboflavin corneal collagen cross-linking. Curr Eye Res 35(8):715-721. https://doi.org/10.3109/02713683.2010. 481068

12. Eljarrat-Binstock E, Domb AJ (2006) Iontophoresis: a noninvasive ocular drug delivery. $\mathrm{J}$ Control Release 110(3):479-489. https://doi.org/10.1016/j.jconrel.2005.09. 049

13. Mastropasqua L, Nubile M, Calienno R et al (2014) Corneal cross-linking: intrastromal riboflavin concentration in iontophoresis-assisted imbibition versus traditional and transepithelial techniques. Am J Ophthalmol. https://doi. org/10.1016/j.ajo.2013.11.018

14. Al Fayez MF, Alfayez S, Alfayez Y (2015) Transepithelial versus epithelium-off corneal collagen cross-linking for progressive keratoconus: a prospective randomized controlled trial. Cornea 34(10):S53-S56. https://doi.org/10. 1097/ICO.0000000000000547

15. Soeters N, Wisse RPL, Godefrooij DA, Imhof SM, Tahzib NG (2015) Transepithelial versus epithelium-off corneal cross-linking for the treatment of progressive keratoconus: a randomized controlled trial. Am J Ophthalmol 159(5):821-828.e3. https://doi.org/10.1016/j.ajo.2015.02. 005

16. Kymionis GD, Grentzelos MA, Portaliou DM, Kankariya VP, Randleman JB (2014) Corneal collagen cross-linking (CXL) combined with refractive procedures for the treatment of corneal ectatic disorders: CXL plus. J Refract Surg
30(8):566-576. 20140711-10

https://doi.org/10.3928/1081597X-

17. Iselin KC, Baenninger PB, Bachmann LM, Bochmann F, Thiel MA, Kaufmann C (2020) Changes in higher order aberrations after central corneal regularization-a comparative two-year analysis of a semi-automated topographyguided photorefractive keratectomy combined with corneal cross-linking. Eye Vis. 7(10):1-10. https://doi.org/10.1186/ s40662-020-00179-2

18. Burris TE, Ayer CT, Evensen DADJ (1991) Effects of intrastromal corneal ring size and thickness on corneal flattening in human eyes. Refract Corneal Surg 7(1):46-50

19. Sakellaris D, Balidis M, Gorou O, Szentmary N (2019) intracorneal ring segment implantation in the management of keratoconus: an evidence-based approach. Ophthalmol Ther 8(s1):5-14. https://doi.org/10.1007/s40123-01900211-2

20. Chou B, Boxer WBS (2000) Intacs for a keratocone: a promising new option? Rev Optom 137(4):97

21. Kwitko S, Severo NS (2004) Ferrara intracorneal ring segments for keratoconus. J Cataract Refract Surg 30(4):812-820. https://doi.org/10.1016/j.jcrs.2003.12.005

22. Jabbarvand M, Hashemi H, Mohammadpour M, Khojasteh H, Khodaparast M, Hashemian H (2014) Implantation of a complete intrastromal corneal ring at 2 different stromal depths in keratoconus. Cornea 33(2):141-144. https://doi. org/10.1097/ICO.0000000000000026

23. Vega-Estrada A, Alio JL (2016) The use of intracorneal ring segments in keratoconus. Eye Vis 3(1):1-7. https://doi.org/ 10.1186/s40662-016-0040-z

24. Keenan TDL, Jones MNA, Rushton S, Carley FM (2012) Trends in the indications for corneal graft surgery in the United Kingdom: 1999 through 2009. Arch Ophthalmol 130(5):621-628. https://doi.org/10.1001/archophthalmol. 2011.2585

25. Dua HS, Faraj LA, Kenawy MB et al (2018) Dynamics of big bubble formation in deep anterior lamellar keratoplasty by the big bubble technique: in vitro studies. Acta Ophthalmol 96(1):69-76. https://doi.org/10.1111/aos.13460

26. Anwar M, Teichmann KD (2002) Big-bubble technique to bare Descemet's membrane in anterior lamellar keratoplasty. J Cataract Refract Surg 28(3):398-403. https://doi. org/10.1016/S0886-3350(01)01181-6

27. Buzzonetti L, Petrocelli G, Valente P (2012) Femtosecond laser and big-bubble deep anterior lamellar keratoplasty: a new chance. J Ophthalmol. https://doi.org/10.1155/2012/ 264590

28. Guindolet D, Nguyen DT, Bergin C, Doan S, Cochereau I, Gabison EE (2018) Double-docking technique for femtosecond laser-assisted deep anterior lamellar keratoplasty. Cornea 37(1):123-126. https://doi.org/10.1097/ICO. 0000000000001442

29. Price FW, Price MO, Grandin JC, Kwon R (2009) Deep anterior lamellar keratoplasty with femtosecond-laser zigzag incisions. J Cataract Refract Surg 35(5):804-808. https://doi.org/10.1016/j.jcrs.2009.01.011

30. Shehadeh-Mashor R, Chan C, Yeung SN, Lichtinger A, Amiran M, Rootman DS (2013) Long-term outcomes of femtosecond laser-assisted mushroom configuration deep anterior lamellar keratoplasty. Cornea 32(4):390-395. https://doi.org/10.1097/ICO.0b013e318254a4e4 
31. Pedrotti E, Cozzini T, Fasolo A et al (2019) Small-incision lenticule addition in ex vivo model of ectatic human corneas. Int Ophthalmol 39(11):2575-2581. https://doi.org/10. 1007/s10792-019-01106-8

32. Mastropasqua L, Nubile M, Salgari N, Mastropasqua R (2018) Femtosecond laser-assisted stromal lenticule addition keratoplasty for the treatment of advanced keratoconus: a preliminary study. J Refract Surg. 34(1):36-44

33. Yam GHF, Yusoff NZBM, Goh TW et al (2016) Decellularization of human stromal refractive lenticules for corneal tissue engineering. Sci Rep 6(May):1-11. https://doi.org/10. 1038/srep26339

34. Park SE, Tseng M, Lee JK (2019) Effectiveness of intracorneal ring segments for keratoconus. Curr Opin Ophthalmol 30(4):220-228. https://doi.org/10.1097/ICU. 0000000000000582

35. Pedrotti E, Caldarella G, Fasolo A et al (2019) Topographic and biomechanical changes after application of corneal cross-linking in recurrent keratoconus. Int J Environ Res Public Health 16(20):1-9. https://doi.org/10.3390/ ijerph16203872

36. Ganesh S, Brar S (2015) Femtosecond intrastromal lenticular implantation combined with accelerated collagen cross- linking for the treatment of keratoconus-initial clinical result in 6 eyes. Cornea 34(10):1331-1339. https://doi.org/ 10.1097/ICO.0000000000000539

37. Mohammadpour M, Heidari Z, Hashemi H (2018) Updates on managements for keratoconus. J Curr Ophthalmol 30(2):110-124. https://doi.org/10.1016/j.joco.2017.11.002

38. Van Dijk K, Liarakos VS, Parker J et al (2015) Bowman layer transplantation to reduce and stabilize progressive, advanced keratoconus. Ophthalmology 122(5):909-917. https://doi.org/10.1016/j.ophtha.2014.12.005

39. Khaled ML, Bykhovskaya Y, Gu C et al (2019) PPIP5K2 and PCSK1 are candidate genetic contributors to familial keratoconus. Sci Rep 9(1):1-16. https://doi.org/10.1038/ s41598-019-55866-5

40. Naderan M, Mohammadpour M, Farjadnia M (2015) Gene therapy in keratoconus. Oman J Ophthalmol 8(1):3. https:// doi.org/10.4103/0974-620x.149854

Publisher's Note Springer Nature remains neutral with regard to jurisdictional claims in published maps and institutional affiliations. 